\title{
Green synthesis, characterization, antioxidant, antibacterial, and photocatalytic activity of Suaeda maritima (L.) Dumort aqueous extract-mediated copper oxide nanoparticles
}

\author{
Pavani Peddi ${ }^{*}$ (D), Prasada Rao PTSRK ${ }^{2}$, Nannapaneni Usha Rani ${ }^{1}$ and S. Lakshmi Tulasi ${ }^{1}$
}

\begin{abstract}
Background: The aim of this work was to synthesize copper oxide nanoparticles (CuO NPs) utilizing heartwood aqueous extract of Suaeda maritima (L.) Dumort. The synthesis of CuO NPs using green methodology with small size and high stability paved the way to protect the environment by not involving toxic chemicals and environment-friendly methodology for pharmacological and photocatalytic applications. The aqueous areal parts extract of S. maritima (L.) Dumort was used for synthesis, characterization of CuO NPs was studied, and further its antioxidant, antibacterial, and photocatalytic activity for the removal of methylene blue was studied.

Results: The synthesized CuO NPs shows characteristic UV-visible absorption maximum at $282 \mathrm{~nm}$. The FT-IR spectra shows peak at $3640 \mathrm{~cm}^{-1}$ attributed to hydrogen bonded $\mathrm{O}-\mathrm{H}$ group of poly phenols, alcohols, and $\mathrm{N}-\mathrm{H}$ of amide. Strong peak at $1122 \mathrm{~cm}^{-1}$ corresponds to $\mathrm{C}-\mathrm{OH}$ stretch in phenols and alcohols. Peaks at $1467 \mathrm{~cm}^{-1}$ and $1585 \mathrm{~cm}^{-1}$ corresponds to $C=C$ in aromatic compounds. Strong peak at $1749 \mathrm{~cm}^{-1}$ represents the $C=O$ in aldehydes or in keto compounds. Several strong bonds identified in the range of 1088 to $1225 \mathrm{~cm}^{-1}$ representing C-O-C stretch vibrations. The synthesized particles were circular in shape with rough surface morphology and dispersed as clusters with size of $37 \mathrm{~nm}$ with metallic content of 73.8\%. The synthesized CuO NPs were proved as potent antibacterial and antioxidant activities. The photocatalytic for the removal of methylene blue in aqueous solution was studied and results proved that the CuO NPs were effectively remove the dye up to $86.91 \%$ within less time of 75 min. Hence, the CuO NPs synthesized are high efficiency with less particle size and can be used as antioxidant, antibacterial agent, and also applicable for the removal of hazardous methylene blue dye from effluents and can contribute indirectly to clean up the environment.

Conclusions: The investigation reports the eco-friendly, cost-effective method for synthesizing copper oxide nanoparticles from S. maritima extract with biomedical applications.
\end{abstract}

Keywords: Green synthesis, Copper nanoparticles, Suaeda maritima, Pharmacological activity, Photocatalytic activity

\footnotetext{
* Correspondence: pavanipeddi7@gmail.com

'Department of Chemistry, Prasad V Potluri Siddhartha Institute of

Technology, Kanuru, Vijayawada, AP 520007, India

Full list of author information is available at the end of the article
}

\section{Springer Open}

(- The Author(s). 2021 Open Access This article is licensed under a Creative Commons Attribution 4.0 International License, which permits use, sharing, adaptation, distribution and reproduction in any medium or format, as long as you give appropriate credit to the original author(s) and the source, provide a link to the Creative Commons licence, and indicate if changes were made. The images or other third party material in this article are included in the article's Creative Commons licence, unless indicated otherwise in a credit line to the material. If material is not included in the article's Creative Commons licence and your intended use is not permitted by statutory regulation or exceeds the permitted use, you will need to obtain permission directly from the copyright holder. To view a copy of this licence, visit http://creativecommons.org/licenses/by/4.0/. 


\section{Background}

In recent years, nanoparticles (NPs) technology plays significance role in the field of medical, pharmaceutical, and textile industries [1]. NPs and nanomaterials were used in different purposes like diagnosis, targeted drug delivery, cosmetics, biosensor, and many more. Metal NPs have different size, shape, composition, and exhibit different and unique physico-chemical properties. In view of this, different researchers around the world are exploring the versatile characteristics and applications of NPs $[2,3]$. Metal NPs such as copper, tin, iron, zinc, and nickel have remarkable applications in biomedical, energy, and environment fields of study [4].

Silver, zinc, gold, etc. metal NPs are having remarkable applications in medical institutes for some years [5]. NPs were exhibit strong adsorption capability which is responsible for its enriched performance and applications [6]. Metallic NPs having various morphologies and sizes can be synthesized using different physical and chemical methods. These methods involve non-standard procedure, are difficulty to perform, and are expensive. Most of the chemical-mediated NP synthesis utilize toxic chemicals such as reducing agents, non-biodegradable stabilizing agents, and organic solvents. These chemicals are dangerous to biological, aquatic systems and the environment [7]. Thus, the synthesis of NPs using biological methods is proved as environmental friendly and economical and is served as the best alternative method for synthesis of NPs. In biological NP synthesis methods, microbes and bioactive plant extracts are used as reducing agent. The growing of microbial culture for a long period is very difficult and there is a possibility of contamination and hence use of plant bioactive compounds for the NP synthesis is very simple, economical, and convenient [8].

In recent days, copper $(\mathrm{Cu})$, nickel $(\mathrm{Ni})$, zinc $(\mathrm{Zn})$, etc. are used for NP synthesis instead of noble metals such as gold and silver because noble metals are rare and high cost. Copper oxide $(\mathrm{CuO})$ NPs have a wide range of application in different fields and are used in catalytic [9], optical [10], superconductor [11], and magnet resistance materials [12] and solar energy transformation [13] applications. CuO NPs also having antimicrobial [14], antidiabetic, anti-cancer [15], and biocidal [16] properties. $\mathrm{CuO}$ NPs are nontoxic and having antimicrobial efficacy in controlling plant diseases, photocatalytic activity for dye effluent treatment, and many other environmental applications [17].

The Suaeda maritima (L.) Dumort., belongs to the family Amaranthaceae, commonly known as seablite and locally called as Elakura in Andhra Pradesh. It is grown in coastal salt flats and tidal wetlands near the sea and is distributed worldwide. It is edible as a leaf vegetable and used for making juice and curries, feeding cattle, goats, and sheep [18]. In local traditional medicine, it is used for the treatment of hepatitis and is having hepatoprotective [19], antioxidant [20], and antimicrobial [21] activities.

In the literature survey, to the best of our knowledge, there are no reports available for the synthesis of $\mathrm{CuO}$ NPs using any part of the plant $S$. maritima. In view of the above, the present investigation is focused on the synthesis and characterization of $\mathrm{CuO}$ NPs using aqueous whole plant extract of $S$. maritima. In addition, antibacterial activity and DPPH radical scavenging activity of the synthesized $\mathrm{CuO}$ NPs were studied.

Methylene blue is a heterocyclic aromatic compound and a cationic dye, widely used for dying cotton, wool, and silk. The harmful effect of the existence of this dye in waste water may have arisen from the burns effect of eye, nausea, vomiting and diarrhea, etc. It may be poisonous if it is inhaled and in contact with skin. Thus, it is necessary to remove such a hazardous dye from industrial effluent before it pollutes the nearby freshwater streams. Hence, in the present study, the application of the synthesized $\mathrm{CuO}$ NPs for the photocatalytic degradation of methylene blue was also investigated.

\section{Methods \\ Materials}

Copper (II) sulfate penta hydrate, 2,2-diphenyl-1-picrylhydrazyl (DPPH), peptone, beef extract, agar, methylene blue, and sodium hydroxide were purchased from Merck Chemicals, Mumbai. The areal parts of the plant S. maritima (L.) Dumort., was collected in mangrove forest, near Gilakaladindi, Machilipatnam, Krishna District, AP. The field studies were conducted in accordance with the local legislations and have taken necessary permissions. The collected areal plant parts were cleaned, shade dried, powdered, and used for $\mathrm{CuO}$ NP synthesis.

Table 1 Phytochemical screening results of areal parts aqueous extract of Suaeda maritima (L.) Dumort

\begin{tabular}{lll}
\hline S No & Phytochemicals & $\begin{array}{l}\text { Results observed for } \\
\text { S. maritima aqueous extract }\end{array}$ \\
\hline 1 & Alkaloids & - \\
2 & Flavonoids & +++ \\
3 & Phenolic compounds & + \\
4 & Terpenoids & ++ \\
5 & Steroids & - \\
6 & Cardiac glycoside & ++ \\
7 & Proteins & + \\
8 & Carbohydrates & + \\
9 & Amino acids & - \\
10 & Saponins & ++ \\
\hline
\end{tabular}

"+++", immensely present; "++", moderately present; "+", slightly present; "-" absent 


\section{Preparation of plant extract}

Two grams of dried plant powder was added in $200 \mathrm{~mL}$ distilled water in a 500-mL flask, mixed well on a magnetic stirrer with hotplate at $60{ }^{\circ} \mathrm{C}$ for $20 \mathrm{~min}$. Then, it was filtered using Whatman \#1 paper and the filtrate was preserved for NP synthesis and also for the evaluation of phytochemical constituents in the aqueous plant extract by preliminary screening tests as per reported methods [22].

\section{Synthesis of CuO NPs}

The one pot green synthesis of $\mathrm{CuO}$ NPs was performed as per the procedure available in literature [23, 24] briefly, to $50 \mathrm{~mL}$ of $5 \mathrm{mM}$ copper sulfate solution, $5 \mathrm{~mL}$ of extract was added and $\mathrm{pH}$ was adjusted to 7 using 1
$\mathrm{N}$ sodium hydroxide solution. The color changed to green color and the solution was centrifuged and pellet was dried in air oven at $60{ }^{\circ} \mathrm{C}$ for $24 \mathrm{~h}$. A dark brown/ black color powder was obtained and was stored in room temperature for further study.

\section{Characterization of CuO NPs}

The double beam UV-visible spectrophotometer (JASCO, Japan) was used for determination of optical absorption of $\mathrm{CuO}$ NPs in the wavelength region of 800 to $200 \mathrm{~nm}$. The nature of the bioactive compounds involved in the bioreduction of $\mathrm{Cu}$ was identified by performing functional group identification on Fourier transform infrared spectroscopy (FT-IR, Bruker, USA) which is performed in 4000 to $500 \mathrm{~cm}^{-1}$ range. FE-SEM (field emission scanning
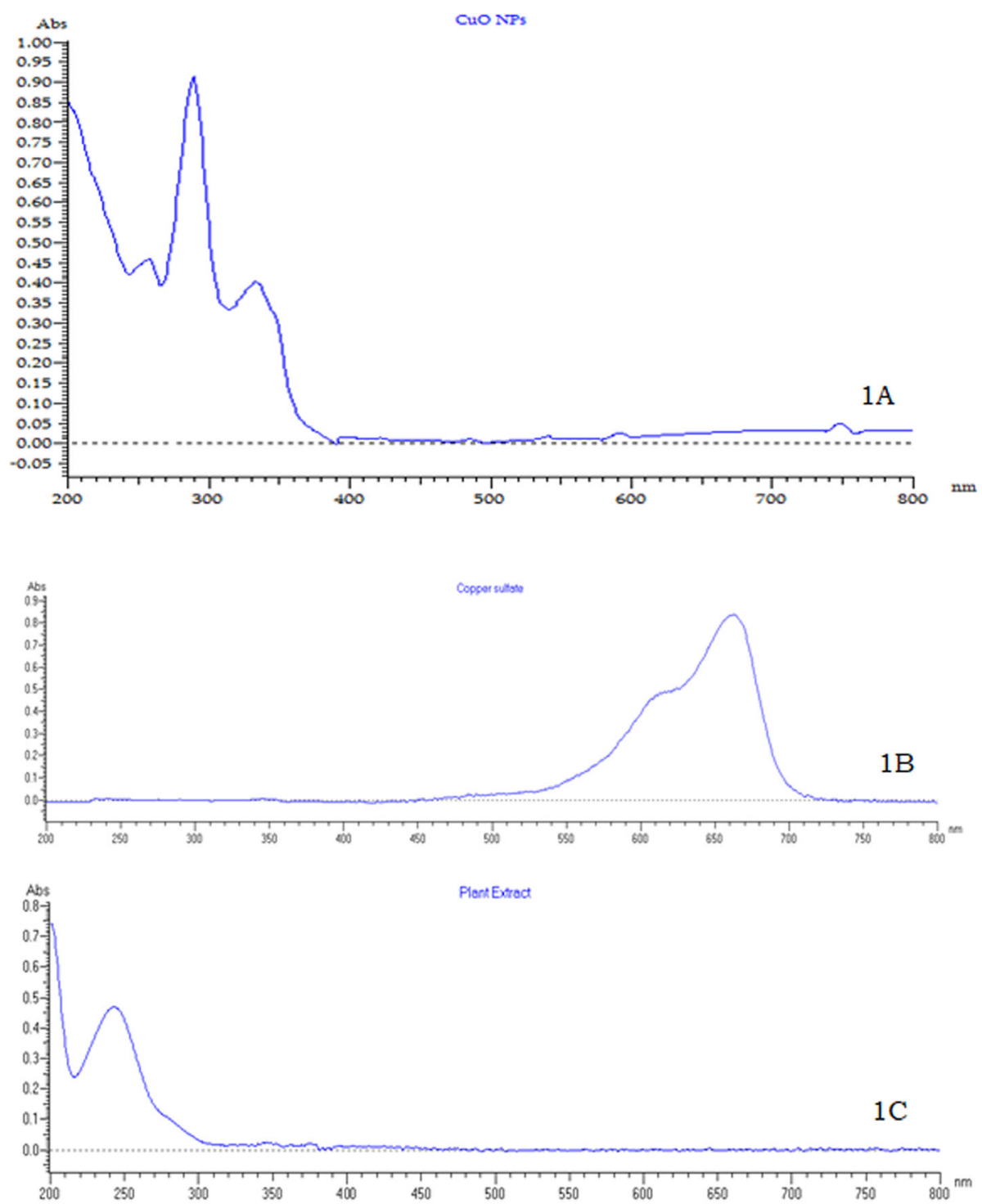

Fig. 1 UV-visible absorption of spectra of CuO NPs synthesized using S. maritima extract (A), copper sulfate aqueous solution (B), and aqueous plant extract $(\mathbf{C})$ 
electron microscope - Nova, Nanosem-450, FEI, USA) study was carried for the determination of morphology and size of the synthesized NPs. X-ray diffractometer (Rigaku Corporation) was studied for the determination of crystalline and lattice structure of the NPs and is carried at a scan speed of $2 \%$ min in the diffraction angles $(2 \theta)$ from 20 to $80^{\circ}$. Energy-dispersive X-ray spectroscopy (RONTEC's EDX system, Model QuanTax 200, Germany) studies were carried for the determination of elemental composition of the synthesized NPs. The zeta potential and size distribution of the NPs were determined using dynamic light scattering (DLS) technology using Malvern Zetasizer (Nano ZS90, UK) at $25^{\circ} \mathrm{C}$, at an angle of $17{ }^{\circ} \mathrm{C}$ and 78.5 dielectric constant $[25,26]$.

\section{Antibacterial activity of synthesized CuO NPs}

The antibacterial activity of synthesized NPs was carried against two gram-positive and two gram-negative bacteria namely Bacillus subtilis (MTCC - 1427) and Staphylococcus aureus (MTCC - 1430) and two gramnegative bacteria namely Escherichia coli (MTCC 294) and Pseudomonas aeruginosa (MTCC - 1748) using well diffusion method on nutrient agar plate as per the procedure described by Priyanka et al. [27]. In a sterile petri dish, $10 \mathrm{~mL}$ of nutrient agar medium was poured as a basal layer followed with $15 \mathrm{~mL}$ of seeded medium previously inoculated with selected bacterial suspension (100 mL of medium $/ 1 \mathrm{~mL}$ of $\left.10^{7} \mathrm{CFU}\right)$ to attain $10^{5} \mathrm{CFU} / \mathrm{ml}$ of medium. Then, wait till the complete solidification of the medium in the petri plate and wells were prepared using sterilized stainless-steel cork borer. In each well, $25 \mu \mathrm{L}$ of selected concentration of aqueous plant extract, NPs solution, and Gentamycin (standard) were loaded with a sterile micro-pipette. Simultaneously

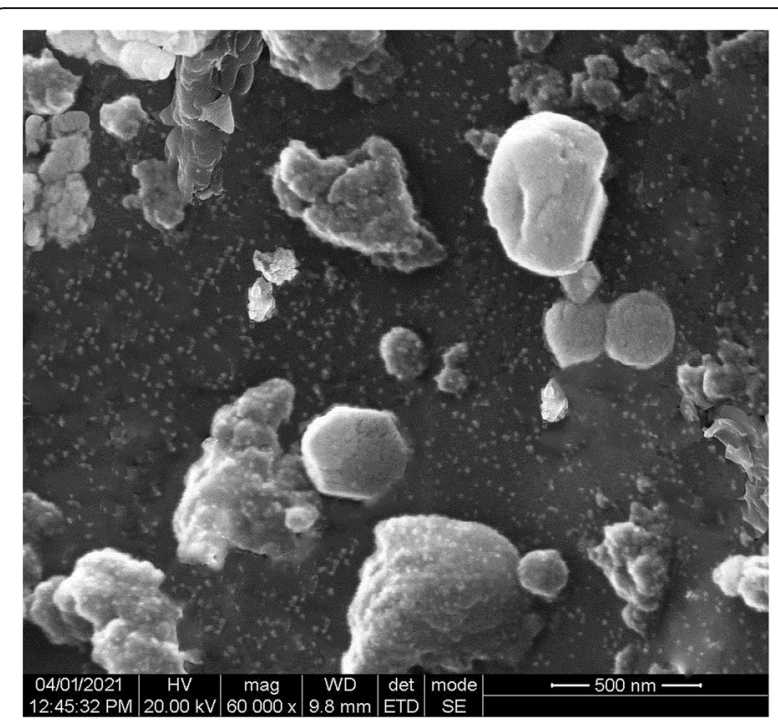

Fig. 3 SEM photo of S. maritima (L.) Dumort aqueous areal parts extract based $\mathrm{CuO}$ NPS

in a separate petri dish, water was loaded and served as negative control and plates were grown at $37^{\circ} \mathrm{C}$ for 24 h. Then, the zone of inhibition of standard, CuO NPs. and aqueous plant extract were measured in millimeters by comparing with negative control.

\section{DPPH radical scavenging assay of synthesized CuO NPs}

The DPPH free radical scavenging assay of synthesized $\mathrm{CuO}$ NPs was carried out by the method of described by Thirunavukkarasu et al. [28]. In $1 \mathrm{~mL}$ of $0.135 \mathrm{mM}$ methanolic DPPH solution, $1 \mathrm{~mL}$ of different concentrations of synthesized $\mathrm{CuO}$ NPs and aqueous plant extract were added separately and the reaction mixture was

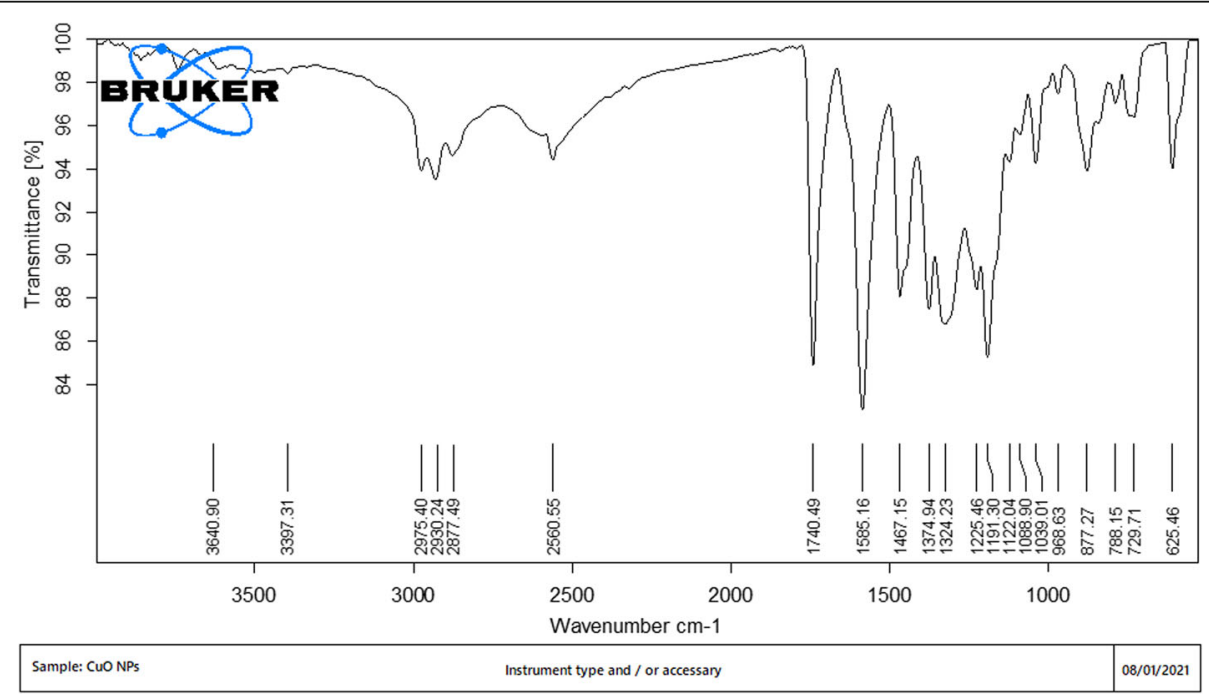

Fig. 2 FT-IR analysis spectrum of S. maritima (L.) Dumort aqueous areal parts extract based CuO NPs 


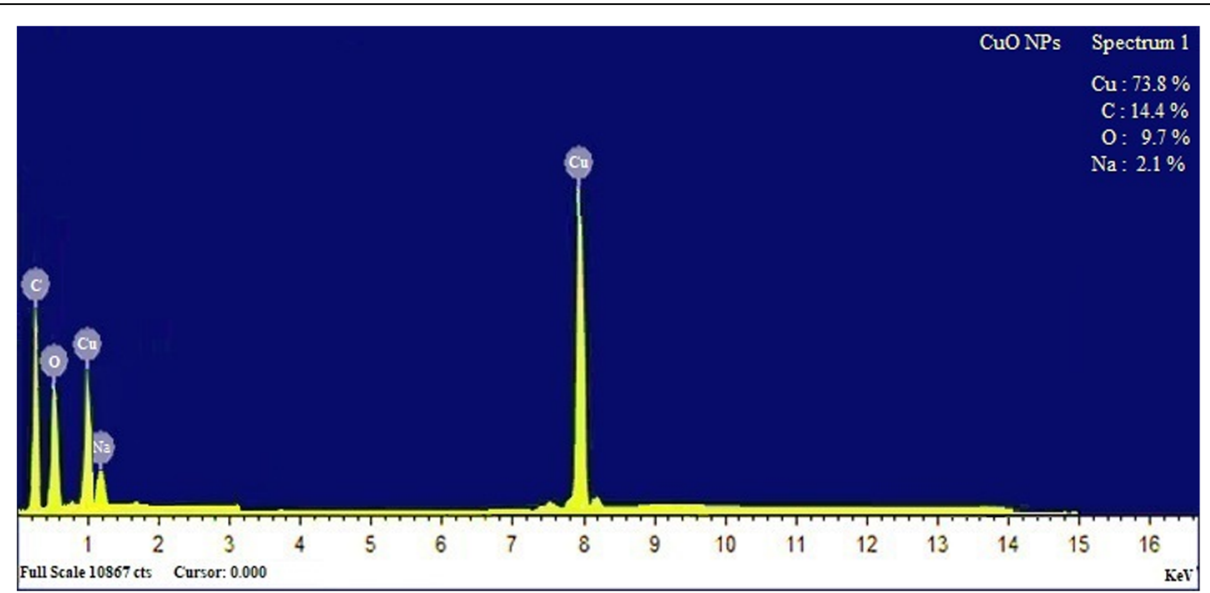

Fig. 4 EDX profile of CUO NPS

incubated in room temperature for $30 \mathrm{~min}$. The absorbance of the resultant solution was measured using UV-visible spectrophotometer at $517 \mathrm{~nm}$. The DPPH inhibition activity of the synthesized nanoparticles was calculated using the resultant absorbance vales with that of the control values.

\section{Photocatalytic degradation of methylene blue}

Standard methylene blue solution at a concentration of $50 \mu \mathrm{g} / \mathrm{mL}$ and $100 \mu \mathrm{g} / \mathrm{mL}$ was selected for the photocatalytic efficiency S. maritima (L.) Dumort mediated $\mathrm{CuO}$ NPs. The standard dye solution was treated with different strengths of synthesized $\mathrm{CuO}$ NPs and was kept in sunlight. Then, with an interval of every $1 \mathrm{~h}, 2.0 \mathrm{~mL}$ of dye solution was taken and centrifuged at $3000 \mathrm{rpm}$ for $5.0 \mathrm{~min}$. The supernatant solution absorbance was determined by UV-visible spectrophotometer at $664 \mathrm{~nm}$ and the $\%$ dye present in the solution and the $\%$ dye degraded due to the treatment with $\mathrm{CuO}$ NPs was calculated using standard calibration curve [29].

\section{Results}

The phytochemical analysis results of S. maritima (L.) Dumort aqueous extract was given in Table 1.

The aqueous extracts of areal parts of plant S. maritima (L.) Dumort was used for the synthesis of $\mathrm{CuO}$ NPs. The formation of green color may be surface plasmon vibrations with copper oxide nanoparticles which confirms the bio-reduction of copper and the formation of $\mathrm{CuO}$ NPs. The bio-reduction of copper and the formation of NPs were checked using UV-visible spectrophotometer (Fig. 1).

The surface analysis of $\mathrm{CuO}$ NPs synthesized using $S$. maritima (L.) Dumort as bio-stabilizing agent gives an idea about the involvement of biomolecules that are responsible for the reduction and the capping of nano-

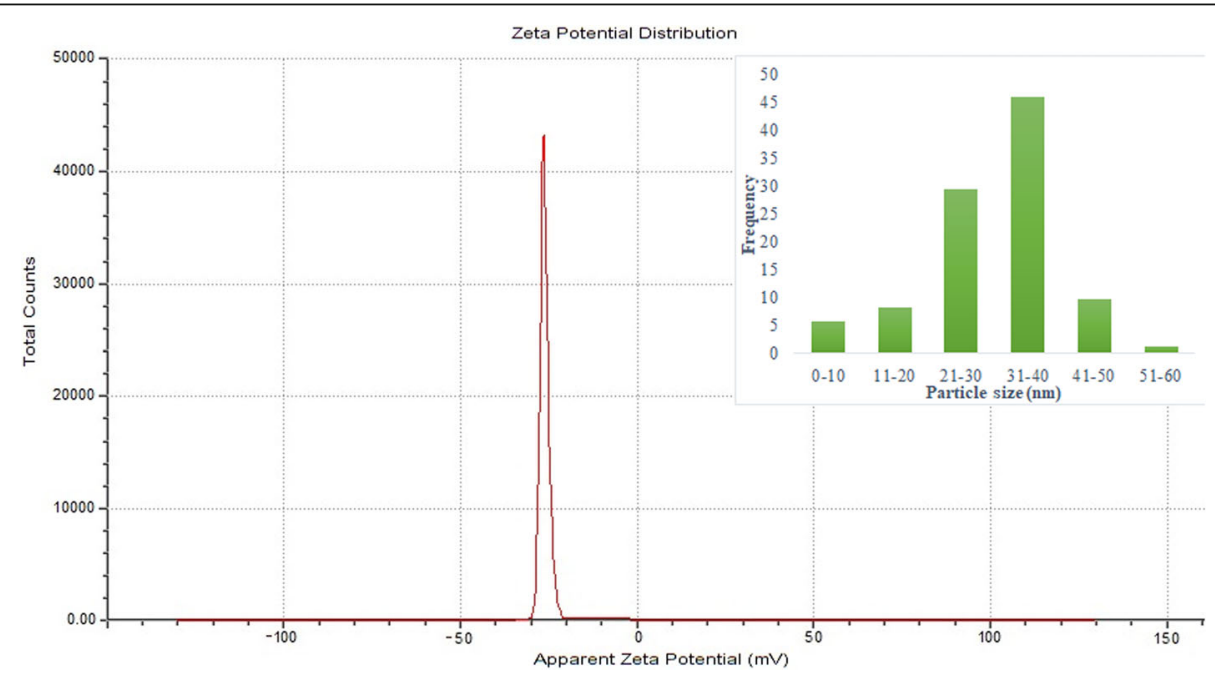

Fig. 5 Zeta potential and particle size distribution of CuO NPs 


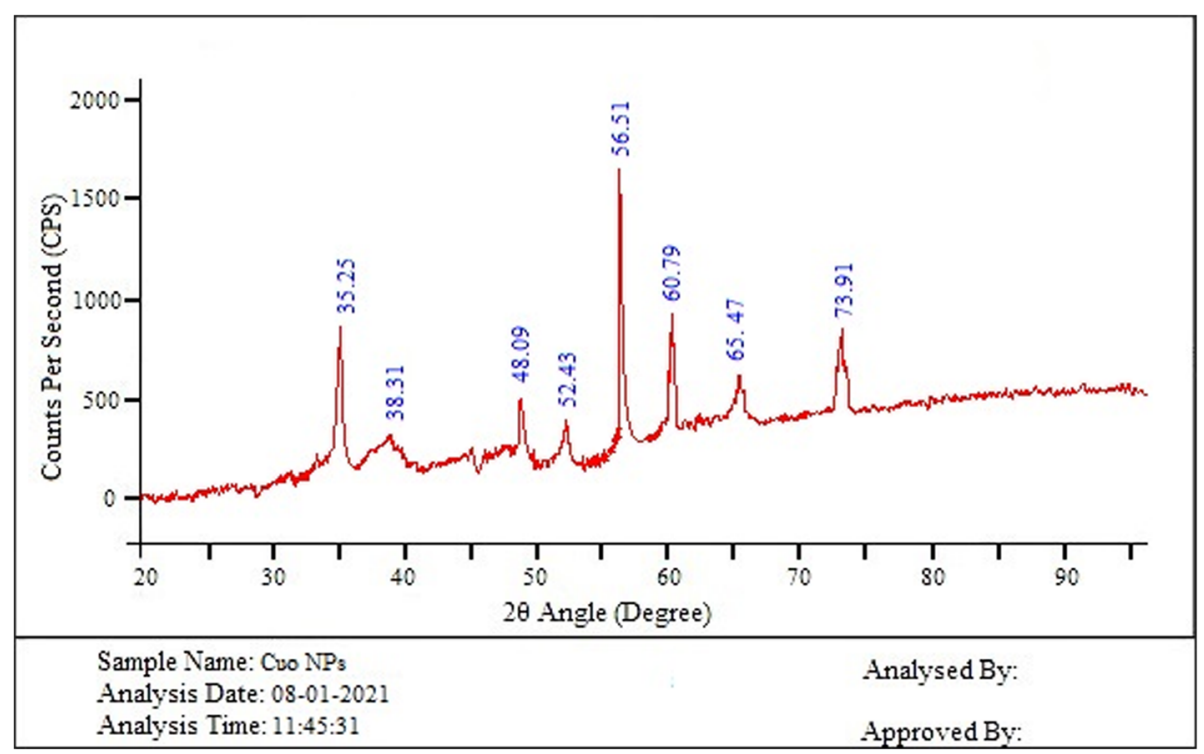

Fig. 6 XRD spectra of CuO NPs Antibacterial activity study

composites. The FT-IR spectra of the CuO NPs (Fig. 2) shows absorption peaks due to bio molecules present in the plant extract and reflects the complex nature of the NPs. The FT-IR spectra shows peak at $3640 \mathrm{~cm}^{-1}$ attributed to hydrogen bonded $\mathrm{O}-\mathrm{H}$ group of poly phenols, alcohols, and N-H of amide. Strong peak at $1122 \mathrm{~cm}^{-1}$ corresponds to $\mathrm{C}-\mathrm{OH}$ stretch in phenols and alcohols. Peaks at $1467 \mathrm{~cm}^{-1}$ and $1585 \mathrm{~cm}^{-1}$ corresponds to $\mathrm{C}=\mathrm{C}$ in aromatic compounds. Strong peak at $1749 \mathrm{~cm}^{-1}$ represents the $\mathrm{C}=\mathrm{O}$ in aldehydes or in keto compounds. Several strong bonds identified in the range of 1088 $\mathrm{cm}^{-1}$ to $1225 \mathrm{~cm}^{-1}$ representing stretch vibrations in CO-C bond.

The micrograph observed in SEM analysis of synthesized $\mathrm{CuO}$ NPs is shown in Fig. 3. The SEM micrograph shows agglomerations of the NPs and the shape of the NPs was observed to be circular with rough surface morphology and dispersed as clusters. The size of the obtained $\mathrm{CuO}$ NPs was in 10-60 $\mathrm{nm}$ size range.

The elemental composition of S. maritima (L.) Dumort extract-mediated $\mathrm{CuO}$ NPs was confirmed by EDX analysis and the spectrum was given in Fig. 4.
Dynamic light scattering (DLS) technology is used for the determination of particle size distribution of synthesized $\mathrm{CuO}$ NPs. The results found that $\mathrm{CuO}$ NPs were distributed in the size of less than $60 \mathrm{~nm}$. The maximum abundance of size distribution was observed in $21-40 \mathrm{~nm}$. The less than $10 \mathrm{~nm}$ and greater than $50 \mathrm{~nm}$ size particles were very less and having $37 \mathrm{~nm}$ as average size of the particles and is further confirmed using XRD analysis. The DLS technology is also utilized for evaluation of zeta potential of $\mathrm{CuO}$ NPs. The results show that the $\mathrm{CuO}$ NPs were a negative change and was observed at $26.6 \mathrm{mV}$ (Fig. $5)$. The high negative zeta potential causes strong repulsion between the particles [24] and the particles formed in this study was found to be stable.

The crystalline nature and phase orientation of the synthesized $\mathrm{CuO}$ NPs was determined using XRD studies. The XRD pattern shows the peaks position with $2 \theta$ values of $35.25^{\circ}, 38.31^{\circ}, 48.09^{\circ}, 52.43^{\circ}, 56.51^{\circ}, 60.79^{\circ}, 65^{\circ}$, $47^{\circ}$, and $73.91^{\circ}$ (Fig. 6) are indexed as (002), (111), (202), (020), (202), (113), (311), and (113) planes. From the XRD spectra, the interplanar spacing and lattice

Table 2 Antibacterial activity results of aqueous extract of S. maritima (L.) Dumort and its mediated CuO NPS

\begin{tabular}{|c|c|c|c|c|c|c|c|}
\hline \multirow[t]{2}{*}{ S No } & \multirow{2}{*}{$\begin{array}{l}\text { Organism } \\
\text { studied }\end{array}$} & \multicolumn{2}{|c|}{ Sample at $100 \mu \mathrm{g} / \mathrm{mL}$ concentration of } & \multicolumn{2}{|c|}{ Sample at $10 \mu \mathrm{g} / \mathrm{mL}$ concentration of } & \multicolumn{2}{|c|}{ Sample at $1.0 \mu \mathrm{g} / \mathrm{mL}$ concentration of } \\
\hline & & Plant extract & CuO NPs & Plant extract & CuO NPs & Plant extract & CuO NPs \\
\hline 1 & B. subtilis & 7.6 & 17.1 & 5.1 & 9.4 & 2.3 & 5.7 \\
\hline 2 & S. aureus & 7.1 & 16.5 & 4.6 & 9.8 & 2.1 & 5.9 \\
\hline 3 & E. coli & 9.1 & 14.3 & 3.2 & 7.5 & 0 & 3.9 \\
\hline 4 & P. aeruginosa & 8.6 & 15.8 & 3.9 & 8.1 & 0 & 4.2 \\
\hline
\end{tabular}

Values given in the table are the average of three replicate experiments 


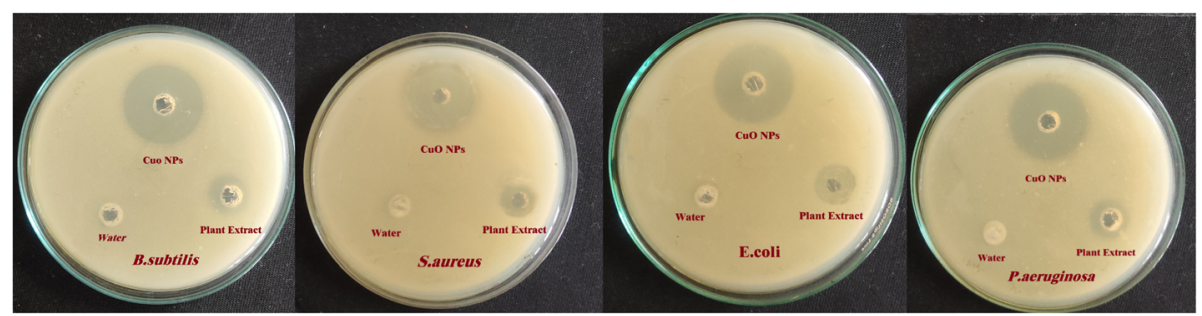

Fig. 7 Images of antibacterial activity results of aqueous extract of S. maritima (L.) Dumort and its mediated CuO NPS

parameter values were calculated and was found to be $0.2269 \mathrm{~nm}$ and $0.3983 \mathrm{~nm}$ respectively which are in correlation with the standard International Center of Diffraction Data card (JCPDS-45-0937) for $\mathrm{CuO}$ NPs confirms that the formed NPs are in crystalline nature with an average particle size of $34 \mathrm{~nm}$.

The synthesized $\mathrm{CuO}$ NPs show potential growth inhibition against bacterial strains studied. The results of the antibacterial activity confirm that the activity was enhanced for the synthesized $\mathrm{CuO}$ NPs than water extract and the results were given in Table 2; zone of inhibition was represented in Fig. 7 and the graphical comparison of different studied concentrations against bacterial strains was shown in Fig. 8.

The DPPH free radical assay of $\mathrm{CuO} \mathrm{NPs}$ and the aqueous plant extract was compared with ascorbic acid (standard) and aqueous plant extract. It was obtained that both plant aqueous extract and the synthesized $\mathrm{CuO}$ NPs having DPPH inhibition activity and are compared with that of standard ascorbic acid. The IC 50 of standard ascorbic was found to be $23.67 \mu \mathrm{g} / \mathrm{mL}$, whereas the green synthesized $\mathrm{CuO}$ NPs was found to be 28.05 $\mu \mathrm{g} / \mathrm{mL}$ which is very close to the standard and the aqueous plant extract has $51.71 \mu \mathrm{g} / \mathrm{mL}$. The results confirm that $\mathrm{CuO}$ NPs have enhanced radical inhibition activity than aqueous extract and are very close to standard. The results of DPPH inhibition study were given in Table 3 and the comparison graph was represented in Fig. 9.

\section{Photocatalytic degradation of methylene blue}

The photocatalytic activity of $\mathrm{CuO}$ NPs was studied for the degradation of methylene blue dye using UV-visible spectrophotometer at $664 \mathrm{~nm}$. The activity was confirmed by carrying a control experiment without NPs. It was confirmed that the dye was kept in sunlight without $\mathrm{CuO}$ NPs; there is no change in the strength/concentration and remarkable decrease in strength of dye in presence of $\mathrm{CuO}$ NPs (Fig. 10a) and reached minimum at time interval of $120 \mathrm{~min}$ (Fig. 10b). The concentration of methylene blue dye in each time interval was calculated using standard calibration curve (Fig. 10c). At a concentration of $50 \mu \mathrm{g} / \mathrm{mL}$ of methylene blue, the \% degradation was less and at a concentration of $100 \mu \mathrm{g} / \mathrm{mL}$, the $\%$ degradation was high (Fig. 10d). The results of photocatalytic degradation of methylene blue by Cuo NPs

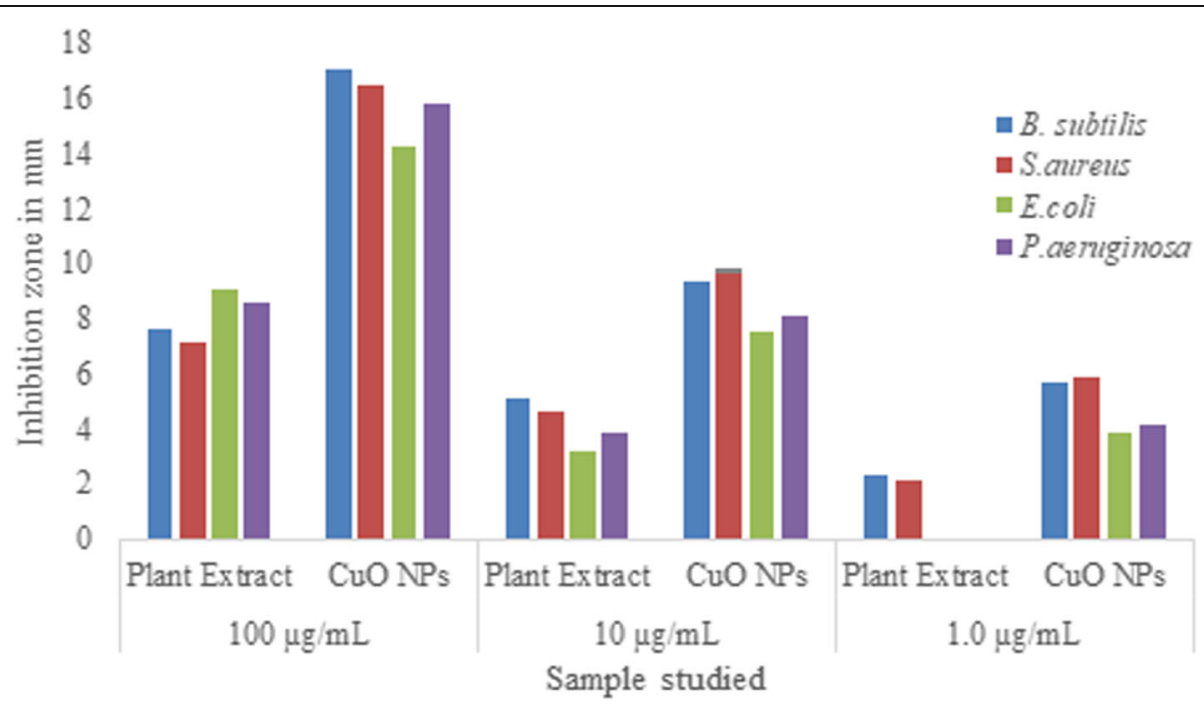

Fig. 8 Comparison of images of antibacterial activity of aqueous plant extract of Suaeda maritima (L.) Dumort and its mediated CuO NPS 
Table 3 Results obtained in DPPH radical scavenging assay

\begin{tabular}{lllll}
\hline $\mathbf{S}$ & \multirow{2}{*}{$\begin{array}{l}\text { Concentration } \\
\text { in } \boldsymbol{\mu g} / \mathbf{m L}\end{array}$} & \multicolumn{3}{l}{ \% DPPH Inhibition } \\
\cline { 3 - 5 } & Ascorbic Acid & Aqueous extract & CuO NPs \\
\hline 1 & 5 & 6.52 & 0.57 & 3.51 \\
2 & 10 & 9.81 & 1.62 & 5.93 \\
3 & 15 & 21.89 & 3.71 & 12.55 \\
4 & 20 & 34.69 & 8.56 & 24.64 \\
5 & 25 & 53.91 & 16.83 & 38.93 \\
6 & 30 & 69.73 & 23.88 & 54.67 \\
7 & 35 & 82.68 & 31.69 & 68.44 \\
8 & 40 & 95.21 & 39.52 & 83.91 \\
\hline
\end{tabular}

Values given in the table are the average of three replicate experiments

synthesized using S. maritima (L.) Dumort aqueous extract was shown in Table 4.

\section{Discussion}

The UV-visible absorbance spectra show wavelength maxima centered near $282 \mathrm{~nm}$ (Fig. 1A) indicating the reduction of copper sulfate to $\mathrm{CuO}$ NPs. The similar type of UV absorption peak was reported in the literature and provides correlation with the present study [30]. There is no absorption peak in the region of 282 $\mathrm{nm}$ observed in the UV spectra of aqueous copper sulfate solution (Fig. 1B) and aqueous plant extract (Fig. 1C) confirms that the absorption peaks at $282 \mathrm{~nm}$ is due to the formation of $\mathrm{CuO}$ NPs. In the UV-visible spectra, there is another peak at $328 \mathrm{~nm}$ was observed and this may be due to the presence of bioactive compounds in the plant extract that are responsible for the formation of $\mathrm{CuO}$ NPs.
The FT-IR analysis of $\mathrm{CuO}$ NPs confirms that flavonoids, phenolic compounds, terpenoids, cardiac glycoside, and saponins are the chemical constitutes shows positive in the preliminary screening of the aqueous extract of $S$. maritima may be acts as reducing, stabilizing, and dispersing agent for $\mathrm{CuO}$ NPs formation. In addition to the plant-based bioactive compounds, the characteristic vibrational peak corresponding to $\mathrm{CuO}$ NPs was observed at $625 \mathrm{~cm}^{-1}$ conforms the formation of copper NPs [31, 32]. The SEM micrograph shows, size of the obtained $\mathrm{CuO}$ NPs was in 10-60 $\mathrm{nm}$ size range.

The EDX study of the chemical composition of $\mathrm{CuO}$ NPs confirms that $\mathrm{Cu}$ was observed at an atomic percentage of $73.8 \%$, the other elements carbon, oxygen, and sodium were detected in the EDX spectra with an atomic percentage of $14.4,9.7$, and $2.1 \%$, respectively. The results confirm that the NPs are formed with $\mathrm{Cu}$ and $\mathrm{O}$. The presence of carbon and oxygen in the NPs originated from the bioactive chemical constituents present in the aqueous extract of $S$. maritima. The atomic \% of copper was found to be high. Oxygen composition was low than the carbon and less composition of sodium was detected in the EDX spectra. The detection of sodium in the EDX spectra may be origin from the plant which is grown in the mangrove soils and salt is deposited in the plant tissues. Polydispersity index (PDI) is the parameter used to indicate the uniformity and the homogeneity of the NPs and PDI of less than 0.2 is preferred for monodispersity. In the present study, the PDI of the NPs synthesized using S. maritima aqueous plant extract was found to be 1.593 which corroborated the monodispersity of the NPs. In the XRD spectra, no peaks corresponding to other phases

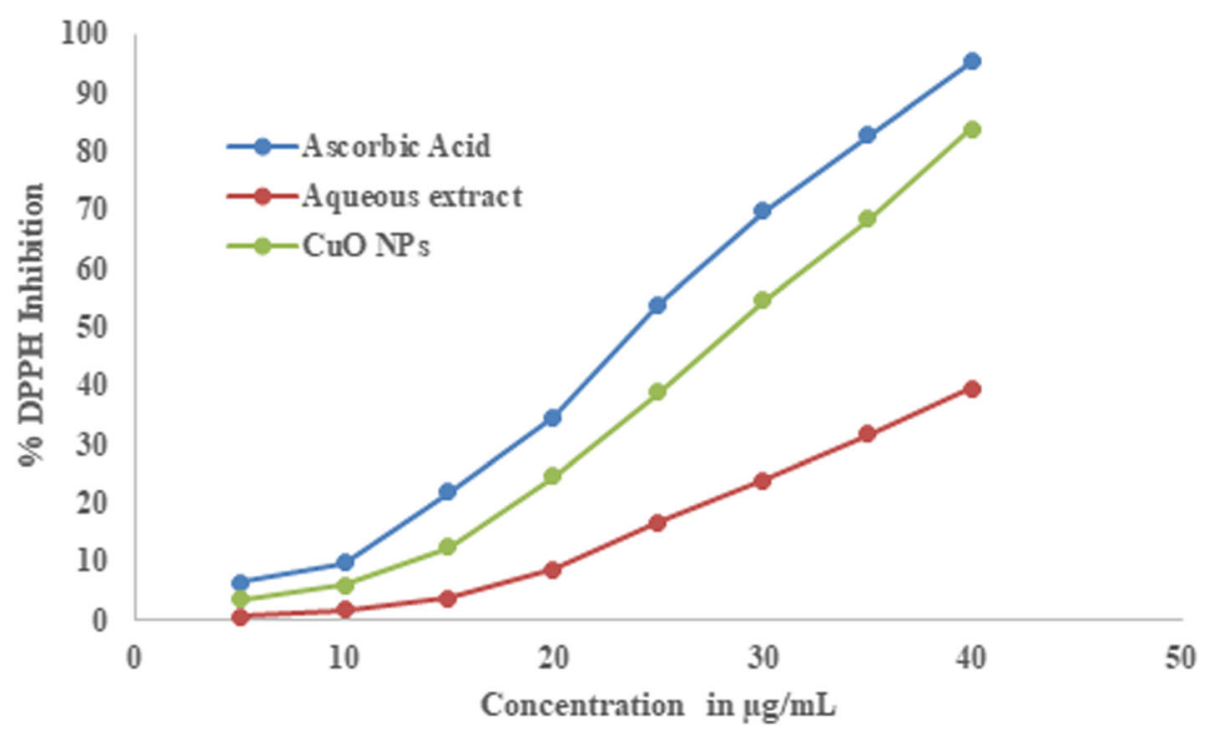

Fig. 9 Comparative graph of DPPH assay study results of standard ascorbic acid, aqueous extract of S. maritima (L.) Dumort, and Cuo NPS synthesized in the study 


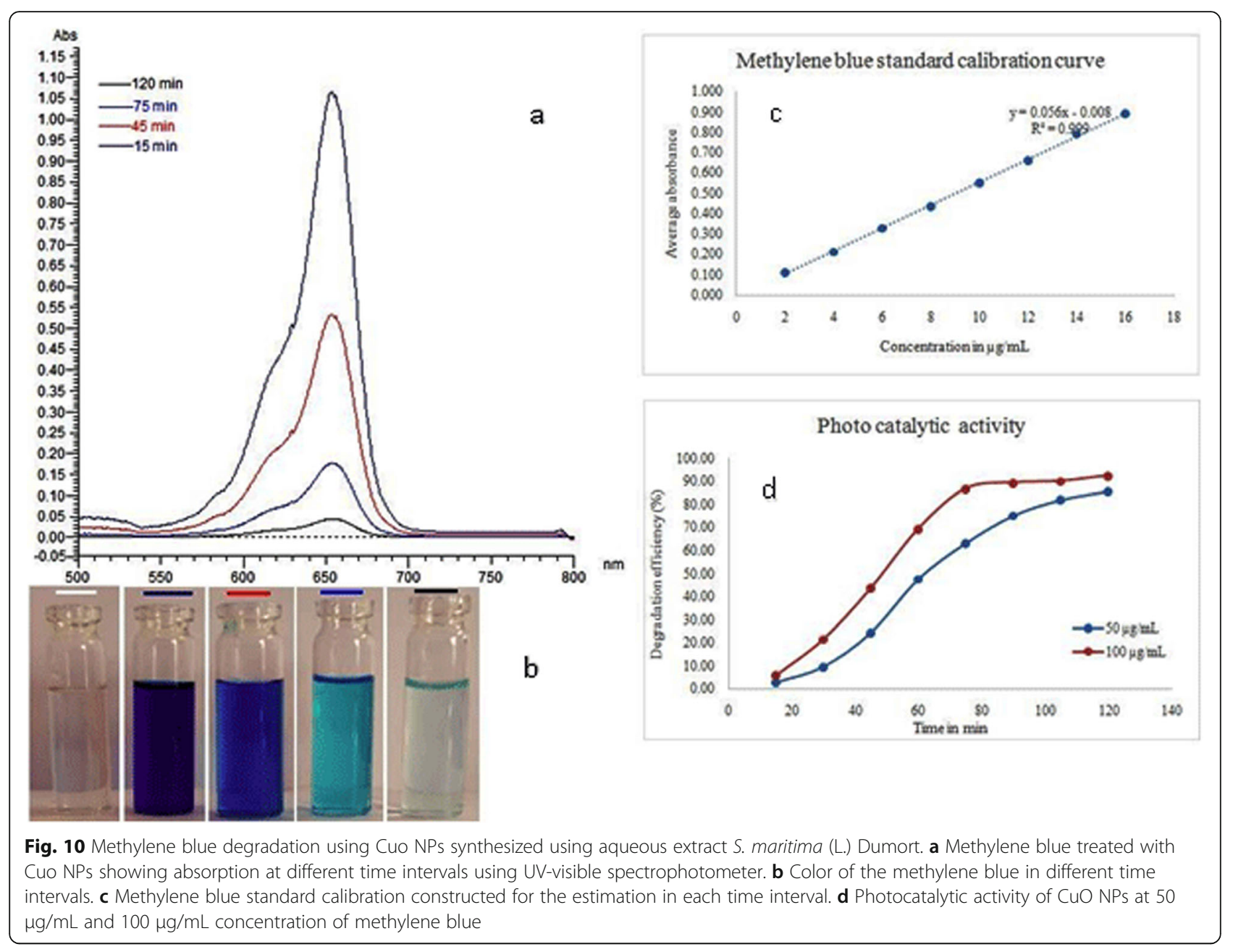

detected confirm that $\mathrm{CuO}$ NPs were pure and other phases were involved in the structure. The DebyeScherrer equation [33] was utilized for evaluation of crystallite size of the synthesized $\mathrm{CuO}$ NPs and the average size obtained was $34 \mathrm{~nm}$ which is in good

Table 4 Methylene blue photocatalytic activity results of $\mathrm{CuO}$ NPs synthesized using aqueous extract of S. maritima (L.)

Dumort

\begin{tabular}{|c|c|c|c|}
\hline \multirow{2}{*}{$\begin{array}{l}\text { S } \\
\text { No }\end{array}$} & \multirow{2}{*}{$\begin{array}{l}\text { Time } \\
\text { in } \\
\text { min }\end{array}$} & \multicolumn{2}{|c|}{$\%$ Photocatalytic degradation at a concentration of } \\
\hline & & $50 \mu \mathrm{g} / \mathrm{mL}$ & $100 \mu \mathrm{g} / \mathrm{mL}$ \\
\hline 1 & 15 & 2.84 & 5.93 \\
\hline 2 & 30 & 9.73 & 21.58 \\
\hline 3 & 45 & 24.45 & 43.71 \\
\hline 4 & 60 & 47.61 & 69.52 \\
\hline 5 & 75 & 63.22 & 86.91 \\
\hline 6 & 90 & 75.13 & 89.57 \\
\hline 7 & 105 & 82.01 & 90.23 \\
\hline 8 & 120 & 85.70 & 92.55 \\
\hline
\end{tabular}

Value given in the table are the average of three replicate experiments correlation with the results observed in particle size distribution.

The extract and the synthesized $\mathrm{CuO}$ NPs show antibacterial activity against the bacterial strains studied. Aqueous plant extract at $1 \mu \mathrm{g} / \mathrm{mL}$ concentration shows no zone of inhibition for $E$. coli and $P$. aeruginosa whereas in same concentration prominent zones were observed for $\mathrm{CuO}$ NPs. The zone of inhibition in all the studied concentration was found to be more for synthesized $\mathrm{CuO}$ NPs than water extract and no zone of inhibition observed for control.

In photocatalytic degradation of methylene blue, it was observed that more and more dye molecules were adsorbed on the surface of the photocatalyst, when initial concentration of the dye was increased. Because many active sites were occupied by the dye molecules, the adsorption of $\mathrm{O}_{2}$ and $\mathrm{OH}^{-}$on the photocatalyst was decreased, which leads to reduced generation of radicals. Furthermore, the photons were blocked before reaching the photocatalyst surface; hence, the adsorption of photons was decreased by the photocatalyst. Accordingly, the removal rate reduced at high initial dye 
concentrations. The photocatalytic degradation of methylene blue results confirms that \% degradation with time was found to be more efficient in the present study and are in correlation with the finding reported [34, 35].

The NPs synthesized using chemical synthesis have limitations such as stability in hostile environment, lack of understanding in fundamental mechanism and modeling factors, bioaccumulation/toxicity features, expansive analysis requirements, need for skilled operators, problem in devices assembling and structures, and recycle/reuse/regeneration. But the present study is the green synthesis approach and NPs produced through regulation, control, clean up, and remediation process will directly help uplift their environmental friendliness.

\section{Conclusions}

The study highlighted the utilization of S. maritima (L.) Dumort in the domain of nanotechnology and synthesized $\mathrm{CuO}$ NPs. The FT-IR spectra of $\mathrm{CuO}$ NPs shows the presence of bioactive functional groups that are present in the plant extracts are the responsible for the bio-capping of the $\mathrm{CuO}$ NPs. The synthesized $\mathrm{CuO}$ NPs were characterized and confirms that the particle size of around $34 \mathrm{~nm}$ having circular in shape with rough surface morphology. The synthesized $\mathrm{CuO}$ NPs were found to be potent against growth of common microbial pathogens and are also having DPPH radical inhibition antioxidant activity. The synthesized $\mathrm{CuO}$ NPs exploited as photocatalyst exhibited excellent degradation efficiency methylene blue dye. The \% degradation of dye was higher than the reported methods and was confirmed to be advantaged than the reported. Thus, the presented method is quick, convenient, environment-friendly, nontoxic, and free from organic solvents, surfactants, and specialized instruments.

\section{Abbreviations}

CuO NPs: Copper oxide nanoparticles; CuO: Copper oxide; NPs: Nanoparticles; UV-Vis: UV-visible spectrophotometry; XRD: X-ray diffraction; FT-IR: Fourier transform infrared spectroscopy; SEM: Scanning electron microscopy

\section{Acknowledgements}

The authors of the article are thankful to Siddhartha Academy for providing the research facilities.

\section{Authors' contributions}

PP conducted the research and writing of the manuscript. PTSRK has assisted, analyzed the data, and performed initial drafting of the manuscript, and SLT and NUR executed the experimental works and analyzed data. PP was responsible for designing the research and approving the final content of the manuscript. The authors have read and approved the final manuscript.

\section{Funding}

Not applicable.

Availability of data and materials Not applicable.

\section{Declarations}

Ethics approval and consent to participate

Not applicable.

\section{Consent for publication}

Not applicable.

\section{Competing interests}

The authors declare that they have no competing interests.

\section{Author details}

'Department of Chemistry, Prasad V Potluri Siddhartha Institute of Technology, Kanuru, Vijayawada, AP 520007, India. ${ }^{2}$ Department of Chemistry, P.B. Siddhartha College of Arts and Science, Vijayawada, AP 520010, India.

Received: 3 July 2021 Accepted: 11 August 2021

Published online: 30 August 2021

\section{References}

1. Ramesh P, Rajendran A, Meenakshisundaram M (2014) Green synthesis of zinc oxide nanoparticles using flower extract Cassia auriculata. J Nanosci Nanotechnol 2:41-45

2. Folorunso A, Akintelu S, Oyebamiji AK, Ajayi S, Abiola B, Abdusalam I, Morakinyo A (2009) Biosynthesis, characterization and antimicrobial activity of gold nanoparticles from leaf extracts of Annona muricata. J Nanostr Chem 9(2):111-117

3. Esmaeili E, Salavati NM, Mohandes F, Davara F, Seyghalkarb H (2011) Modified single-phase hematite nanoparticles via a facile approach for large-scale synthesis. Chem Eng J 170(1):278-285. https://doi.org/10.1016/j.cej.2011.03.010

4. Akintelu SA, Folorunso AS, Ademosun OT (2019) Instrumental characterization and antibacterial investigation of silver nanoparticles synthesized from Garcinia kola leaf. J Drug Deliv Therapeut 9(6):58-64

5. Akintelu SA, Folorunso AS (2019) Biosynthesis, characterization and antifungal investigation of Ag-Cu nanoparticles from bark extracts of Garcina kola. Stem Cells 10(4):30-37

6. Khatereh P, Heshmatollah H, Mahmoud N (2019) Green synthesis of $\mathrm{Ni@Fe3O4} \mathrm{and} \mathrm{CuO} \mathrm{nanoparticles} \mathrm{using} \mathrm{Euphorbia} \mathrm{maculata} \mathrm{extract} \mathrm{as}$ photocatalysts for the degradation of organic pollutants under UVirradiation. Ceram Int 45:17173-17182

7. Happy Agarwal, Venkat Kumar S., Rajesh Kumar S., A review on green synthesis of zinc oxide nanoparticles - an eco-friendly approach, ResourceEfficient Technologies, 2017, 3(4): 406-413.

8. Bogunia-Kubik K, Sugisaka M (2002) From molecular biology to nanotechnology and nanomedicine. Biosystems 65(2-3):123-138. https://doi. org/10.1016/S0303-2647(02)00010-2

9. Yang S, Wang C, Chen L, Chen S (2010) Facile dicyandiamide-mediated fabrication of well-defined CuO hollow microspheres and their catalytic application. Mater Chem Phys 120(2):296-301. https://doi.org/10.1016/j.ma tchemphys.2009.11.005

10. Yu T, Cheong FC, Sow CH (2004) The manipulation and assembly of CuO nanorods with line optical tweezers. Nanotechnology 15(12):1732-1736. https://doi.org/10.1088/0957-4484/15/12/005

11. Yip SK, Sauls JA (1992) Nonlinear Meissner effect in CuO superconductors. Phys Rev Lett 69(15):2264-2267

12. Musa AO, Akomolafe T, Carter MJ (1998) Production of cuprous oxide, a solar cell material, by thermal oxidation and a study of its physical and electrical properties. Sol Energy Mater Sol Cells 51(3-4):305-316. https://doi. org/10.1016/S0927-0248(97)00233-X

13. Tamaki J, Shimanoe K, Yamada Y, Yamamoto Y, Miura N, Yamazoe N (1998) Dilute hydrogen sulfide sensing properties of $\mathrm{CuO}-\mathrm{SnO} 2$ thin film prepared by low-pressure evaporation method. Sensors Actuators B Chem 49(1-2): 121-125. https://doi.org/10.1016/S0925-4005(98)00144-0

14. Bogdanović U, Lazic V, Vodnik V, Budimirc M, Dimitrijevic S (2014) Copper nanoparticles with high antimicrobial activity. Mater Lett 128(1):75-78. https://doi.org/10.1016/j.matlet.2014.04.106

15. Noor S, Shah Z, Javed A, Ali A, Hussain SB, Zafar S, Ali H, AunMuhammad S (2020) A fungal based synthesis method for copper nanoparticles with the determination of anticancer, antidiabetic and antibacterial activities. J Microbiol Methods 174:1-13 
16. Nagajyothi PC, Muthuraman P, Sreekanth TVM, Kim DH, Shim J (2017) Green synthesis: in-vitro anticancer activity of copper oxide nanoparticles against human cervical carcinoma cells. Arab J Chem 10:215-225

17. Campos EVR, Proença PLF, Oliveira JL, Bakshi M, Abhilash PC, Fraceto LF (2019) Use of botanical insecticides for sustainable agriculture: future perspectives. Ecol Indic 105:483-495. https://doi.org/10.1016/j.ecolind.2018. 04.038

18. Bandaranayake WM (2002) Bioactivities, bioactive compounds and chemical constituents of mangrove plants. Wetl Ecol Manag 10(6):421-452. https:// doi.org/10.1023/A:1021397624349

19. Ravi Kumar S, Gnanadesigan M, Jacob Inbaneson S, Kalaiarasi A (2011) Hepatoprotective and antioxidant properties of Suaeda maritima (L.) dumort ethanolic extract on concanavalin-A induced hepatotoxicity in rats. Indian J Exp Biol 49(6):455-460

20. Patra J.K., Dhal N.K., and Thatoi H.N., In vitro bioactivity and phytochemical screening of Suaeda maritima (Dumort): a mangrove associate from Bhitarkanika, India, Asian Pacific Journal of Tropical Medicine, 2011: 727-734.

21. Bulti Nayak, Satarupa Roy, Madhumita Roy, Mitra A., and Kalpana Karak, Phytochemical, antioxidant and antimicrobial screening of Suaeda maritima $L$ (Dumort) against human pathogens and multiple drug resistant bacteria., Indian J Pharm Sci, 2018, 80(1):26-35.

22. Mari R, Shirley M, Xavier C, Jaime S, David V, Rosa S, Jodie D (2018) Preliminary phytochemical screening, total phenolic content and antibacterial activity of thirteen native species from Guayas province Ecuador. Journal of King Saud University - Science 30(4):500-505. https:// doi.org/10.1016/j.jksus.2017.03.009

23. Sankar R, Manikandan P, Malarvizhi V, Fathima T (2014) Kanchi Subramanian Shivashangari and Vilwanathan Ravikumar, Green synthesis of colloidal copper oxide nanoparticles using Carica papaya and its application in photocatalytic dye degradation. Spectrochim Acta A Mol Biomol Spectrosc 121(5):746-750. https://doi.org/10.1016/j.saa.2013.12.020

24. Mali SC, Dhaka A, Githala CK, Trivedi R (2020) Green synthesis of copper nanoparticles using Celastrus paniculatus Willd., leaf extract and their photocatalytic and antifungal properties. Biotechnology Reports 27:1-9

25. Pasupuleti VR, Prasad T, Shiekh RA (2013) Biogenic silver nanoparticles using Rhinacanthus nasutus leaf extract, synthesis, spectral analysis, and antimicrobial studies. Int J Nanomedicine 8:3355-3364. https://doi.org/1 $0.2147 /$ IJN.S49000

26. Gokce EH, Korkmaz E, Tuncay TS, Dellera E, Sandri G, Bonferoni MC, Ozer O (2012) A comparative evaluation of coenzyme Q10-loaded liposomes and solid lipidnanoparticles as dermal antioxidant carriers. Int J Nanomedicine 7: 5109-5117

27. Anandgaonker P, Kulkarni G, Gaikwad S, Rajbhoj A (2019) Synthesis of TiO2 nanoparticles by electrochemical method and their antibacterial application. Arab J Chem 2(8):1815-1822

28. Kumar TS, Rahuman AA, Jayaseelan C, Rajakumar G, Marimuthu S, Kirthi AV, Velayutham K, Thomas J, Venkatesan J, Kim S-K (2014) Green synthesis of titanium dioxide nanoparticles using Psidium guajava extract and its antibacterial and antioxidant properties. Asian Pac J Trop Med:968-976

29. Roshitha S, Mithra V, Saravannan V, Senthil KS, Gnanadesigan M (2019) Photocatalytic degradation of methylene blue and safranin dyes using chitosan zinc oxide nano-beads with Musa paradisiaca L. pseudo stem. Bioresource Technology Reports 5:339-342. https://doi.org/10.1016/j.biteb.2 018.08 .004

30. Ghidan AY, Al-Antary TM, Awwad AM (2016) Green synthesis of copper oxide nanoparticles using Punica granatum peels extract: effect on green peach aphid. Environmental Nanotechnology, Monitoring \& Management 6: 95-98. https://doi.org/10.1016/j.enmm.2016.08.002

31. Hassanien R., Al-Said S.A.F, Siller L., Little R., Wright N.G., Houlton A., and Horrocks B.R., Smooth and conductive DNA-templated $\mathrm{Cu}_{2} \mathrm{O}$ nanowires: growth morphology, spectroscopic and electrical characterization, Nanotechnology, 2012, 23(7): 075601, DOl: https://doi.org/10.1088/0957-44 84/23/7/075601.

32. Shoeib MA, Abdelsalam OE, Khafagi MG, Hammam RE (2012) Synthesis of Cu2O nanocrystallites and their adsorption and photocatalysis behavior. Adv Powder Technol 23(3):298-304. https://doi.org/10.1016/j.apt.2011.04.001

33. Vidhu VK, Aromal A, Philip D (2011) Green synthesis of silver nanoparticles using Macrotyloma uniflorum. Spectrochim Acta A 83(1):392-397. https://doi. org/10.1016/j.saa.2011.08.051

34. Chandraker SK, Lal M, Ghosh MK, Tiwari V, Ghorai TK, Shukla R (2020) Green synthesis of copper nanoparticles using leaf extract of Ageratum houstonianum Mill. and study of their photocatalytic and antibacterial activities. Nano Express 1(1):1-12

35. Jyoti K, Singh A (2016) Green synthesis of nanostructured silver particles and their catalytic application in dye degradation. Journal of Genetic Engineering and Biotechnology 14(2):311-317. https://doi.org/10.1016/j. jgeb.2016.09.005

\section{Publisher's Note}

Springer Nature remains neutral with regard to jurisdictional claims in published maps and institutional affiliations.

\section{Submit your manuscript to a SpringerOpen ${ }^{\circ}$ journal and benefit from:}

- Convenient online submission

- Rigorous peer review

- Open access: articles freely available online

- High visibility within the field

- Retaining the copyright to your article

Submit your next manuscript at $\boldsymbol{\nabla}$ springeropen.com 